\title{
Componentes químicos da madeira de Torresia acreană Ducke
}

\author{
Seiva C. Cascon \\ Layde L. Moura \\ Regina C. A. Lago
}

Torresia acreana Ducke (Leguminosa, Lotoideae) conhecida sob os nomes de "imburana", "amburana", "cumaru de cheiro", "cumarina", é árvore de grande porte, cerca de $30 \mathrm{~m}$ de altura, que ocorre na região amazônica, principalmente no Estado do Acre (Ducke, 1939).

T. acreana e T. cearensis são as únicas espécies conhecidas deste gênero.

T. cearensis Fr. Allem., que ocorre nos cerrados, foi objeto de vários estudos. Freire (1934) e Liberalli (1927) encontraram cumarina em todas as partes da planta, sobretudo nas sementes e na casca do tronco.

Tanto as sementes quanto a madeira fornecem um óleo. Constantes físico-químicas foram determinadas por Liberalli \& Lima (1937), para o óleo das sementes.

A madeira de lei, por sua vez, teve suas características físico-mecânicas descritas por Timotheo (1952).

No presente trabalho, foram examinados os componentes químicos da madeira de $\mathbf{T}$. acreana, a espécie da região amazônica.

Cumarina, ácido vanílico, campesterol, estigmasterol e $\beta$-sitosterol foram isolados e identificados do extrato benzênico da madeira que forneceu, paralelamente, um óleo.

Os principais componentes da fração gra. $x a$ do óleo foram os ácidos oléico, linoléico e palmítico.

Da fração insaponificável do óleo, foram isolados os esteróis acima mencionados e os triterpenos cicloeucalenol, 24-metileno-cicloartanol, além de um terceiro, em menor proporção, cujos dados espectrométricos indicam tratar-se de cicloartenol.
É interessante observar-se que os conhecimentos atuais em alelopatia permitem ensaiar uma explicação sobre a função destes compostos, tanto na biossíntese da planta quanto no seu papel em relação ao meio ambiente.

A cumarina, presente na planta em proporção bastante elevada, é, especificamente, um inibidor de germinação, impedindo a proliferação de outras plantas nas proximidades. Funciona ainda como inibidor de crescimento, tornando mais lenta a incorporação de glicose na síntese da celulose (Masaki, 1973).

O ácido vanílico estimula o crescimento das plantas, em doses pequenas, mas tem efeito contrário, em doses elevadas (Fernand, 1969).

Por outro lado, reconhece-se que a presença de ácidos graxos livres, ou como ésteres de esteróis ou triterpenos se constitui numa defesa contra insetos, tendo sido verificada a ação anti-termítica do éster palmitato de cicloeucalenila (Rudman, 1967).

Os compostos isolados podem ser responsabilizados por certas características da $\mathbf{T}$. acreana bem como por propriedades de preservação e de defesa no meio altamente destrutivo em que vive.

\section{PARTE EXPERTMENTAL}

Torresia acreana foi coletada em abril de 1975, em Mato Grosso do Norte, pelo botânico João Murça Pires do então IPEAN, Belém, Pará. Um espécimen botânico PA 356(146.551), encontra-se no herbário da Instituição.

Quatro $\mathrm{kg}$ de madeira fornecem $40 \mathrm{~g}(1 \%)$ de resíduo benzênico que foi cromatografado em coluna de $280 \mathrm{~g}$ de silicagel. 
A fração oleosa foi eluída com benzeno, a cumarina com benzeno: clorofórmio 8:2, o fi-sitosterol com benzeno: clorofórmio 1:1 e o ácido vanílico com clorofórmio: acetato de etila $8: 2$.

A fração oleosa $(9 \mathrm{~g}, 0,23 \%)$, pouco solúvel em éter etílico e solúvel em clorofórmio, a quente, apresentou as seguintes características: $n^{40} \quad 1,4979 ; n^{50} \quad 1,4935 ; \quad$ I. Iodo (Wijs)

$$
\text { D }
$$$$
\text { D }
$$

69,3; I.S. 107,3; insaponificáveis $58,0 \%$ e ácidos graxos $29,5 \%$.

A composição em ácidos graxos, determinada por cromatografia gás líquido de seus ésteres metílicos, foi a seguinte : ácidos palmítico $(20,76 \%)$ esteárico $(7,59 \%)$, oléico $(44,04 \%)$, linoléico $(12,28 \%)$ e linolênico $(6,77 \%)$ além de terem sido detectados, em quantidade traço, cinco outros ácidos, que não foram, todavia, identificados.

O material insaponificável $(0,22 \mathrm{~g})$ cromatografado em $30 \mathrm{~g}$ de silicagel e eluido com hexana e hexana: éter etílico até a proporção 8:2 mostrou a seguinte constituição : hidrocarbonetos $(9,91 \%)$, duas faixas não identificadas $(1,94$ e $22,31 \%$, respectivamente), álcoois alifáticos e terpênicos $(5,88 \%)$, álcoois terpênicos e esteróis $(43,00 \%)$ e esteróis puros $(7,51 \%)$.

Os álcoois triterpênicos, purificados por cristalização em etanol, foram identificados através de suas características espectrométricas.

Cicloeucalenol, p.f. $135^{\circ}$, lit. $135-137^{\circ}$; IV $S$ $\max (\mathrm{KBr}) 3350 \mathrm{~cm}^{-1}(\mathrm{~m}, \mathrm{OH})$ e $885 \mathrm{~cm}^{-1}$ ( $\left.\mathrm{f},=\mathrm{CH}_{2}\right) ;$ UV $\lambda \max (\mathrm{EtOH}) 209 \mathrm{~nm}$; RNM $\left(\mathrm{CDC}_{3}, 100 \mathrm{MHx}, \diamond\right)$ seis metilas terciárias em $0,91(3 \mathrm{H}, \mathrm{s}), 0,98(3 \mathrm{H}, \mathrm{s}), 1,00(3 \mathrm{H}, \mathrm{s}), 1,10(3 \mathrm{H}, \mathrm{s})$ e $1,30(6 \mathrm{H}, \mathrm{s})$; um grupo metileno em $4,6-4,8$ $(2 \mathrm{H}, \mathrm{d}, \mathrm{J}=2 \mathrm{~Hz})$; dois prótons ciclopropânicos em $0,14-0,19(1 \mathrm{H}, \mathrm{d}, \mathrm{J}=4 \mathrm{~Hz})$ e $0,35-0,45(\mathrm{IH}$, $\mathrm{d}, \mathrm{J}=4 \mathrm{~Hz}$ ); um próton ligado a carbono hidro.

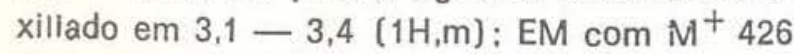
$\left(\mathrm{C}_{30} \mathrm{H}_{50} \mathrm{O}\right)$ e os fragmentos característicos em $\mathrm{m} / \mathrm{e} 353, \mathrm{~m} / \mathrm{e} 365$ e $\mathrm{m} / \mathrm{e} 343$, idênticos aos fragmentos de massa do cicloeucalenol (Audier, 1966).

24-metileno cicloartanol, p.f. $120^{\circ}$, lit. $122^{\circ}$; IV $\checkmark \max (\mathrm{KBr}) 3350 \mathrm{~cm}^{-1}(\mathrm{~m}, \mathrm{OH})$ e $890 \mathrm{~cm}^{-1}$ (f,
$\left.=\mathrm{CH}_{2}\right) ;$ UV $\lambda \max (\mathrm{EtOH}) 209 \mathrm{~nm} ; \mathrm{EM}$ com $\mathrm{M}^{+} 440\left(\mathrm{C}_{31} \mathrm{H}_{52} \mathrm{O}\right)$ e os fragmentos m/e $300, \mathrm{~m} / \mathrm{e}$ 353, m/e 379 e m/e 357 comparáveis aos da literatura (Audier, 1966).

Cicloartenol, p.f. $108-110^{\circ}$, lit. $109^{\circ}$; IV $\mathcal{V}$ $\max (\mathrm{KBr}) 3350 \mathrm{~cm}^{-1}(\mathrm{~m}, \mathrm{OH})$ e $885 \mathrm{~cm}^{-1}$ (f, = $\mathrm{CH}_{2}$ ); UV $\lambda \max (\mathrm{EtOH}) 209 \mathrm{~nm} ; \mathrm{EM}$ com $\mathrm{M}^{+}$ $426\left(\mathrm{C}_{30} \mathrm{H}_{50} \mathrm{O}\right)$ e os fragmentos $\mathrm{m} / \mathrm{e} 411, \mathrm{~m} / \mathrm{e}$ $408, \mathrm{~m} / \mathrm{e} 393$ e m/e 286, comparáveis aos da literatura (Audier, 1966).

Os esteróis, tanto os isolados diretamente do extrato benzênico da madeira, quanto indiretamente (os que estavam presentes no material insaponificável do óleo) foram analisados como acetatos, por cromatografia gás líquido, coluna SE. $30.3 \% \mathrm{em}$ Varaport, 30, 190". Foram identificados os mesmos componentes. campesterol, estigmasterol e $\beta$-sitosterol, nas proporções percentuais $28,57: 27,58: 43,84$ no primeiro caso e $25,51: 58,88: 25,58$ no segundo

$\mathrm{O}$ ácido vanílico foi purificado através de sucessivas cristalizações em etanol. obtendose $20 \mathrm{mg}$ de cristais brancos $(0,001 \%)$ p.f. $207^{\circ}$, lit. 205-206 IV $\checkmark \max (\mathrm{KBr}) 3500 \mathrm{~cm}^{-1}(\mathrm{~m}, \mathrm{OH})$ e $1680 \mathrm{~cm}^{-1}$ (f $\mathrm{CO} \propto-\beta$ insaturada); UV $\lambda \max$ (EtOH) $260 \mathrm{~nm}(\epsilon 10.800)$ e $290 \mathrm{~nm}(\epsilon 3.900)$; RNM (DMSO, $60 \mathrm{MHz}, \delta)$ em $8,30(\mathrm{IH}, \mathrm{m}) 7,50$ $(\mathrm{IH}, \mathrm{d}, \mathrm{J}=\mathrm{IHz}), 7,60(\mathrm{IH}, \mathrm{d}, \mathrm{J}=\mathrm{IHz}), 6,80(\mathrm{IH}$, s), $7,00(\mathrm{IH}, \mathrm{s})$ e $3,9(3 \mathrm{H}, \mathrm{s})$; EM com $\mathrm{M}^{+} 168$ e os fragmentos característicos m/e 153, m/e $121, \mathrm{~m} / \mathrm{e} 98$ e m/e 79 , idênticos aos do espectro de uma amostra padrão.

A cumarina foi purificada por extração com água quente, reextração com clorofórmio e cromatografia sobre $10 \mathrm{~g}$ de silicagel, tendo sido eluída com benzeno: acetato de etila 9:1 $\mathrm{O}$ material obtido apresentou idêntico comportamento ao de um padrão em tlc.

A cumarina foi também comprovada através de reação fotocatalítica específica (Feigl \& Goldstein, 1955), quando se observou, num papel de filtro umedecido com álcali e comprimido de encontro à amostra, o desenvolvimento de fluorescência intensa à luz ultravioleta.

\section{AgradeCIMENTOS}

Ao NPPN, Núcleo de Pesquisas de Produtos Naturais da UFRJ, pelas determinações espectrométricas. 


\section{SUMMARY}

Some compounds present in the wood of Torresia acreana Ducke (Leguminosa, Lotoideae) were identified. Coumarin, vanillic acid, the terpenoids campesterol, stigmasterol, sitosterol, cycloeucalenol, 24-methylene cicloartanol and cycloartenol and some fatty acids chiefly oleic, palmitic and linoleic acids had their presence established by chromatographic and spectrometric methods. The allelopathy of these compounds was discussed.

\section{BIBLIOGRAFIA}

Audier, M.E.; Benzelmaus, L. \& Das, B.S.

1966 - Mass spectroscopy of tetracyclic triterpenes. Part II. The lanostane group: influence of the 9:19 cyclopropane ring. Tetrahedron Letters, New York, 36: 4341-4347.

DUCKE, A.

1939 - As Leguminosas da Amazônia Brasileira, Rio de Janeiro. Serviço Florestal do Ministério da Agricultura, p. 110.

Feigl, F.H. \& Goldstern, D.

1955 - A sensitive specific test for coumarin through photocatalysis. J. Am. Chem. Soc., Easton, 77: 4162-63,
FERNAND, J.

1967 - Phenolic acids as plant growth regulators. Fr. 1.500 .496 , cf CA $70: 2670 n$.

FreIRE, Z.W.

1934 - Brazilian plants explored for their coumarin. Perf. Essent. Oil. Rec., London, 25: 39-40.

Liberalli, C.H. \& Lima, J.

1927 - The Coumarin tree of NE Brazil. Rev. Chim. Ind., Rio de Janeiro, 86: 27-33.

1937 - Coumarin of the Brazil Northeast. Rev. Flora Med, Rio de Janeiro, 3: 341-379.

MasAKI, H. et al.

1973 - Inhibition of byosynthesis of plant cell wall materials, specially cellulose byosynthesis by coumarin. Plant Cell Physiol., Kyoto, 14: 11-28.

RUdMAN, P. \& GAT, F.J.

1967 - The causes of natural durability in timber. $X X I$ - The antitermitic activity of some fatty acids, esters and alcools. Holzforschung, Berlim, 21: 24-26.

Trмотнео, $\mathbf{F}$.

1952 - O cumari das Caatingas, Amburana cearensis (Fr. All.) A.C.Smith. Arq. Serviço Florestal, Rio de Janeiro, 6:1.

(Aceito para publicaçāo em 04/06/79) 